\title{
ADMINISTRAÇĀO - GERAL
}

\section{SERVIÇOS DE ESTADO-MAIOR}

\section{Perspectivas das Ciências da Administração: Diretrizes Metodológicas da Administração Pública}

\author{
Robrert T. Golembiewski \\ Professor Assistente de Administração \\ na Universidade de Illinois
}

(Tradução de Cyro C. Rocha)

A

MARCHA acelerada em busca do desenvolvimento das "ciências administrativas" ameaça deixar a Administração Pública na retaguarda. O sociólogo Whyte explicou a invasão dos limites tradicionais dessa disciplina nos seguintes têrmos: "Podem chamar de invasão ou do que quiserem, mas é uma invasão vitalmente necesssária". $\left({ }^{1}\right)$

Dai êsse esfôrço, que caracteriza a orientação metodológica exigida pela pesquisa científica. $\mathrm{O}$ método de investigação da realidade que se mostrar mais eficaz para fins analiticos deverá ser o preferido. Dar-se-á pouca importância à justificação do método, no sentido convencional, é assunto pertinente à "filosofia da ciência". O material a ser apresentado não constitui pròpriamente novidade, no sentido de que foi tomado por empréstimo à literatura das ciências física e biológica e, com menor frequiência, à do comportamento, que tem proliferado nos últimos tempos. Embora sejam do domínio público, tais dados de ordem metodológica nem sempre estão ao alcance dos estudiosos de administração ou da ciência politica. $\left({ }^{2}\right)$ E nada mais necessário do que a difusão dos conhecimentos e sua aplicação.

(1) Para opiniões divergentes da do autor, vejam-se: Charles Hyneman, am The Study of Politics (Urbana: University of Illinois Press, 1959), especialmente às págs. 75-108 e 151 173, e Vernon VAN DYKe, em Political Science: A Philosofical Analysis (Stanfo-d: Stanford University Press, 1960), especialmente às páginas 191-205.

(2) William F. Whyte, Small Groups and Large Organ'zations, página 311, in John H. Rohrer e Muzafer Sherif, editôres de Social Psichology at the Crosstoads (New York: Harper, 1951). 
O presente trabalho reflete os esforços de um estudioso da Administração Pública interessado em organização. Os problemas e necessidades decorrentes dessa predileção constituem o arcabouço do trabalho. Tais problemas e necessidades não são porém exclusivos dessa disciplina. Nem ela vive ilhada. Conseqüentemente, embora seja o campo aqui muito limitado, os comentários metodológicos são igualmente aplicáveis a outros ramos da Ciência Politica, sujeitos à análise experimental. Todavia, a delimitação completa de tôdas essas áreas seria no momento uma sobrecarga impossivel. Irônicamente, porém, essa análise é decisiva para (digamos) a Politica de Aristóteles. Sua Ética, todavia, para muitos propósitos, pode dispensá-la perfeitamente.

A delimitação rigorosa do assunto é mais uma questão de oportunidade do que de conveniência. A Administração Pública deve ter um desenvolvimento que, sob certo aspecto, é muito peculiar. Isso the valeu maior aproximação dos problemas da análise empírica do que ocorre em outras áreas da Ciência Política. Embora tais progressos tenham suas deficiências notórias, fora de qualquer dúvida, proporcionam não só uma base conveniente e valiosa para as futuras concepções, mas ainda facilitam a transmissão de conhecimentos àqueles com experiência nessa matéria. A necessidade de aproveitar-se o trabalho alheio é manifesta. A grande utilidade da comunicação, quando baseada nas contribuições e necessidades de estudos similares, é òbvia.

\section{I -- CIÊNCIA E ADMINISTRAÇÃO PÚBLICA: O MALÔGRO DO PASSADO \\ E A ALVISSAREIRA PROPOSTA DE SINTETIZAÇÃO}

$\mathrm{O}_{3}$ "quês" e "porquês" da presente concepção e sua comunicação expressam-se, aqui, através de três proposições que delimitam o respectivo campo de ação. Ei-las:

1. que a Administração Pública como disciplina se acha num ponto decisivo do seu desenvolvimento;

2. que a Administração Pública terá maior desenvolvimento, se diversa e mais rigorosa metodologia vier a ser empregada, sempre que possivel;

3. os progressos metodológicos da Administraçâo Pública implicam em pesquisas capazes de produzir não só o treinamento na metodologia adequada, mas ainda resultados que não são triviais em têrmos de interêsses duradouros da disciplina.

Tais proposiçóes não logram preocupar os estudiosos da Administração Pública. De fato, seu modo de lidar com elas pode 
caracterizar-se claramente dessa forma: admitir $1 ;\left({ }^{3}\right)$ discutir 2 , pelo menos para polemizar a possibilidade da existência ou não de uma Ciência de Administração; $\left({ }^{4}\right)$ e nunca procurar de modo geral as pesquisas exigidas por 3. $\left({ }^{5}\right)$

O conflito "ciência-arte" na Administração Pública reflete êsse estado insatisfatório do assunto. Tal controvérsia é bem característica da fase inicial de qualquer disciplina, até firmar-se no rigor metodológico. A Administração Pública, porém, não ultrapassou êsse esfôrço preliminar. As quatro fases centrais da controvérsia ciência-arte explicam êsse tão precário desenvolvimento: um dilúvio de papéis nas décadas dos vinte e dos trinta, tentando adornar a nova disciplina com os atributos de ciência por fôrça da literatura; $\left({ }^{6}\right)$ o renascimento artificial da questão, na década dos quarenta e primeiros anos da dos cinqüenta, centralizada em tôrno do método do "valor livre"; $\left({ }^{7}\right)$ um contraataque dos partidários do método de "política pública", que chegou ao máximo da intensidade nos últimos anos da década dos quarenta, com ênfase especial nos elementos de "valor" na administração, $\left(^{8}\right)$ e a presente diminuição de interêsse em que a idéia dominante é a de que a Administração Pública reflete aspectos

(3) Para um bom exemplo, veja-se FrEDERICK C. MOSHER, "Research on Public Administration: Somes Notes and Suggestions", in Public Administration Review, vol. 16 (Verão de 1956), págs. 169-78.

(4) Notável exceção ao tratamento em geral pouco cuidadoso do assunto é a obra de WAI.DO: The Administrative State: A Study of the Political Theory of the American Public Administration (Nova Iorque, Ronald, 1948) especialmente às págs. 185-86.

(5) Dessa forma, por exemplo, o bem conhecido intercâmbio entre RoBERT A. DAHL, no seu "The Science of Public Administration: Three Problems", in Public Administration Review, vol. 7, (Inverno de 1947), pág. 1-11, e HERBERT Simon, no seu «A Comment on The Science of Public Administration», in Public Administration Review, vol. 7, (Verão de 1947), págs. 200-203, desenvolvida sem base em dados ou pesquisas técnicas.

(6) Veja-se, por exempio, William F. Willouguby, "The Science of Public Administration", especialmente a pág. 39, in Essays in Political Science in Honor of Westel Woodbury Willoughby (Baltimore, The John Hopkins Press, 1937).

(7) Isso, em grande parte, foi resultado do esfôrço de um só homem. Veja-se H. A. Simon, em Administrative Behavior: A Study of the Decision Making Processes in Administrative Organization (edição do Instituto de Tecnologia de Illinois, Chicago, 1945 - N.T.: o livro de H. A. SIMon aqui citado foi traduzido e publicado em 1964 pela Fundação Getúlio Vargas, sob o titulo de "Comportamento Administrativo"); e (Nova Iorque, Macmillan, 1947 e 1956); bem como Public Administration de Donald Smithburg e Victor A. Thompson (Nova Iorque, Knopf, 1950).

(8) A obra mais importante sôbre o assunto é Policy and Administration de Paul H. Appleby (University, Alabama, University of Alabama Press, 1949), especialmente à pág. 10 . 
tanto de ciência como de arte, sem dizer exatamente o que isso significa. $\left({ }^{9}\right)$

Em largos traços, isso conduz a um bêco-sem-saida metodológico. Dessa forma, as primitivas contribuições não estabolecem um método viável para a ciência da Administração Pública. Eram mais esperançosas do que percucientes: refletiam mais o desejo de prestígio de setores denominados "ciências" do que um compromisso metodológico.

O malôgro dêste último "método científico" em atrair apoio significativo e obter um lugar permanente na disciplina é mais complexo. Mas certos elementos nesse malôgro parecem bastante claros e importantes, sob os seguintes aspectos:

1. As circunstâncias eram demasiado gerais para se tornarem "cientificas", sem qualquer indicação clara de onde e como isso poderia acontecer.

2. Muitos estudiosos da Administração Pública alegavam -- ou suspeitavam - que a área de estudo "livice de valores" destinada à Administração Pública era completamenie distinta da necessária a qualificar essa disciplina de cientifica como «realmente é».

3. As tentativas de preparar uma área "livre de valores" no âmbito da Administração Pública, que fôsse parte dêsse último método "cientifico", foi interpretado como contituindo uma redefinição e severa retração dos limites da disciplina.

4. O último método estabeleceu desnecessàriamente uma lifação entre "ciência" em Administração Pública com o "positivismo lógico", o que provocou forte oposição.

5. Alguns ases do "publicismo político" interpretaram o último método como neotradicional e ameaçando restabelecer, em têrmos ligeiramente diferentes, a dicotomia política-administração contra a qual êles sempre levantaram a mais forte e vitoriosa objeção. $\left({ }^{10}\right)$

6. O último "método científico" não conseguiu produzir resultados significativos na disciplina. Além disso,

(9) Dwicht Waldo, The Study of Public Administration, Doubleday Short Studies in Political Science (Garden City, Nova Iorque, 1955), pág. 2 - N.T.: Esta obra acaba de ser traduzida e publicada pela Fundação Getúlio Vargas sob o título de "O Estudo da Administ:ação Pública".

(10) Para interpretação dêsse aspecto do trabalho de SImon, veja-se Norton E. Long, em sua obra "The Goals of Racionality and Responsability", in Public Administration Review, vol. 14 (Inverno de 1954), especialmente à pág. 22. 
o modêlo do último método "livre de valores" - o Administrative Behavior de Simon - é um estudo completo do processo decisório. Trata-se de uma área em que os "elementos de valor" são mais importantes na prática, e dessa forma é um ponto estratégico para a aplicação do método.

As dúvidas tradicionais a respeito de qualquer ciência do comportamento humano também produziram algum pêso sôbre as balanças já sobrecarregadas, contra o argumento vagamente definido em favor da ciência na Administração Pública.

Assim os problemas da análise empírica tiveram acesso à Administração Pública, mas de forma pouco satisfatória. Análise mais cuidadosa é exigida para evitar as falhas que permanecem como prova da atividade primitiva e obstáculos a mudanças metodológicas.

\section{II - CIÊNCIAS: MÉTODO TRÍPLICE ( $\left.{ }^{11}\right)$}

Parte da dificuldade encontrada pela ciência para firmar um lugar na Administração Pública deve-se à falta geral de discussões sôbre o conceito de "ciência", capazes de suportar um exame crítico. Os estudiosos que deixaram alguma marca relativa ao seu modo de compreender a "ciência", quase sempre o fizeram superficialmente. Esta seção tentará remediar a omissão de certa forma, esboçando um modêlo tríplice da "ciência empírica".

\section{A. O Problema.}

Muito da discussão sôbre "ciência", dentro e fora da Administração Pública, começa e acaba, errôneamente, com o método científico. Todavia, a "ciência" não começa com um método, e sim com um problema (isto é, com um "tropêço" para o qual não se acha explicação). Òbviamente, êsse ponto é muitas vêzes esquecido, da inesma forma que o é a implicação manifesta a que conduz: a ênfase numa situação problemática significa que

(11) Em geral, a presente seção participa intensamente da opinião do autor sôbre várias das fontes principais. Algumas dessas fontes aparecem nas notas de rodapé. Outras são: Atom and Cosmos, de Hans Reinchenbach, tradução inglêsa de Edward S. Ali.en (Londres, Allen and Unwin, 1932); Science and First Principles, de F.S.C. Northrop (Nova Iorque, Macmillan, 1932), e The Logic of Sciences and the Humanifies (Nova Iorque, Macmillan, 1948);

The Evolution of Physics de Albert Einstein e L. Infeld (Nova Iorque, Simon and Shuster, 1938); The Foundation of Science: Science and Hypotheses, de Henri Poincaré, tradução de George Bruce Holstead (Nova Iorque. The Science Press, 1913); e Causality and Chance in Modern Physics (Nova Iorque, Harper, 1957). 
em vez de um método de ciência (veja-se abaixo) deve-se falar de métodos especificos e sua relação para com os problemas em consideração. O mesmo se aplica a qualquer outra técnica. Conseqüentemente, um campo de investigação não é excluído do seu "status" específico porque não utiliza os métodos e técnicas de qualquer campo de inquérito geralmente reconhecido como "ciência".

Contudo, certas fases gerais no manejo científico de alguns problemas específicos podem ser isoladas. São as seguintes:

1. a análise do problema particular que conduz a inquérito;

2. a observação indutiva de tipo baconiano dos dados que, na opinião dos analistas de problemas, são considerados importantes;

3. o desenvolvimento de hipóteses oriundas dos dados relevantes; $\mathrm{e}$

4. o teste experimental ou de observação de hipóteses e suas conseqüências lógicas, a demonstração com êxito do teste de utilidade passageira do sistema teórico básico, e sua rejeição, implicando a necessidade de modificar ou rejeitar a referida teoria.

E' preciso cuidado, porém, para não estender demasiado a interpretação dêsse paradigma. Pois dá-se o caso de que certos problemas (de um modo geral, nas ciências físicas) têm sido abordados com mais vigor e êxito do que outros (nas ciências sociais). A experiência com essas áreas mais desenvolvidas devem constituir valiosa fonte de informação para o tratamento de outras áreas. O fato de certo problema não ter sido abordado dêsse modo, todavia, não estabelece sua intocabilidade cientifica.

\section{B. Os Métodos}

As diversas tentativas de aplicar métodos científicos aos problemas administrativos, como se verifica pela literatura sôbre Administração Pública, resultaram inúteis. De fato, embora parte significativa dessa literatura defina "ciência" em têrmos de "método", o significado em geral não é claro. ( $\left.{ }^{12}\right)$

Em grande parte da literatura cientifica, trata-se do "método científico" mas de modo informativo. Contudo, ainda ai, o campo

(12) Marschal E. Dimock, in "Scientific Method and the Future of Political Science", editado por Mathews and Hart, op. cit., pág. 198, reabre uma discussão familiar quando nota que: "em minha opinião a ciência é mais método do que grau de sistematização de resultados... o método cientifico é simplesmente um instrumento". Mas o instrumento ainda não foi usado. 
é vasto. Por exemplo, o eminente físico Bridgman observou cruamente: "O método científico nada mais é do que fazer-se o que bem se quer com a própria mente sem qualquer limitação". $\left({ }^{13}\right)$ E' um tratamento conciso mas sem conteúdo. Dos métodos mais desenvolvidos, três são particularmente dignos de nota. São os seguintes: o método indutivo de Bacon, o dedutivo de Descartes e o hipotético-experimental de Cohen e Nagel. (14) A aparente falta de concordância foi assim apresentada por Northrop: ( $\left.{ }^{15}\right)$

"enquanto Bacon, no tocante a pesquisas, dava tôda ênfase à coleta de dados, e Descartes às deduções lógicas racionais do que estiver fora de dúvidas, Cohen e Nagel exigem de nós a imediata formulação de hipóteses e sua verificação, a fim de determinar se as previsões feitas com base nelas são confirmadas".

As discordâncias em tôrno dos métodos são mais aparentes do que reais, pois o problema existe apenas pelo pressuposto de não haver senão $u \mathrm{~m}$ método científico. Tal pressuposto é insustentável sob diversos aspectos. Pois a situação problemática determina o método. Dessa forma, os métodos empíricos não são nem necessários nem apropriados para certos problemas que levantam sòmente questões de consistência lógica. Além disso, os três métodos acima citados são aplicáveis aos mais variados estágios do desenvolvimento de uma área particular de problema (ou mesmo uma disciplina), como a seção subseqüente indica.

A Administração Pública não evita êsse resultado artificial. Assim, considera um tema central e consistente da primitiva po-

(13) Bridgman, "The Prospect for Intelligence", in Yale Review, vol. 34 (Primavera de 1945), pág. 450.

(14) Francis Bacon, Work, vol. III (Boston, Brown and Taggard, 1862), "Novun Organum: Aforismos Concernentes à Natureza e ao Reino do Homem"; Aforismo XIV: "Nossa única esperança $(\ldots)$ está na verdadeira indução"; Descartes escreveu: "A longa cadeia de simples e fáceis raciocinios, por meio dos quais os geômetras estão acostumados a alcançar conclusões da mais difícil demonstração, jevou-me a imagitur que tôdas as coisas, de cujo conhecimento os homens são capazes, estão interligadas de idêntico modo...". REOÉ DESCARTES, in A Discourse on Method and Selected Writings (Nova Iorque, Dutton, 1945), pág. 16. Finalmente, Morris Cohen e ERNEST Nagel, in An Introduction to Logic and Scientific Method (Nova Iorque. Harcourt, Brace, 1934), págs. 199, 200-201, nota que: "É uma observação inteiramente superficial (..) que a verdade será encontrada pela observação dos fatos $(\ldots)$ Não podemos dar um simples passo à frente em qualquer pesquisa a menos que comecemos com uma explanação sugerida ou uma solução das dificuldades que a originaram. Tais tentativas de explicação são-nos sugeridas por algo do assunto examinado e por nossos conhecimentos anteriores (...). As sugestões formuladas como hipóteses podem ser soluções do problema. Seja o que fôr, é essa a missão da pesquisa". (grifos do original).

(15) Northrop, in Science anda First Principless, pág. 11. 
sição de Simon (o que mais influenciou os estudiosos da disciplina): que o método científico e o lógico (pelo menos até certo ponto) sejam um só e mesmo. Isso é uma ênfase pouco feliz. E' muito ilustrativo que a lógica tradicional esteja preocupada com os conceitos de classe e propriedade e outros semelhantes, ao passo que os conceitos usados em ciência são relacionais. $\left({ }^{16}\right)$

\section{O Estado de Desenvolvimento}

De modo realista, a "ciência" deve ser concebida mais como uma série de estágios de desenvolvimento interdependentes do que como um modêlo de caráter científico descontínuo. Três dêsses estáğios são bastantes para os fins atuais. $\left({ }^{17}\right)$ Seus pontos de ação englobam, respectivamente: (1) o problema-área de análise; (2) a classificação da História Natural, e (3) a formulação dedutiva da teoria.

Essas três fases podem ser descritas de forma sucinta. Na análise do problema-área, primeiro, a ênfase deve incidir diretamente sôbre a determinação das perguntas que devem ser feitas e quais os dados necessários para a compreensão da área do problema. O estágio da História Natural, em segundo lugar, mostra o comêço da pesquisa cumulativa. Todavia, embora o método seja de indução baconiana, o resultado é uma grosseira classificação. Os critérios de classificação são qualitativos e tendem a enfatizar as características superficiais, sendo encontrada sua completa significação (como disse Northrop) "em fatôres que podem ser imediatamente percebidos". O terceiro estágio, da formulação dedutiva da teoria, assenta sôbre os resultados do segundo, desenvolvendo conceitos que não podem ser imediatamente percebidos. (18) Os conceitos nesse estágio são tidos como existentes em virtude de resultarem de um completo processo. De início, desenvolve-se um modêlo do que se propõe que exista. Analisado dedutivamente, êsse modêlo fornece proposições cuja validade pode ser verificada pela experimentação e observação. Os resultados dessa observação ou da experimentação positiva constituem campos conseqüentes para uma "tentativa de realidade", para os conceitos e suas relações que deram lugar aos testes bem sucedidos; uma situação que parece congelada sòmente enquanto são possiveis réplicas e

(16) CARL G. Hempel, in Fundamentals of Concept Formation in Empirical Sicience, vol. II, $\mathrm{n}^{\circ}$ 7, "International Encyclopedia of Unified Science (Chicago University of Chicago Press, 1952), especialmente págs. 4-7.

(17) Northrop, The Logic of the Sciences and the Humanities, para (1), págs. 28-39; para (2) págs. 35-60; e para (3), págs. 60-61.

(18) Assim, na parte inicial dos seus Prinicipia, Newton distinguiu entre o "espaço percebido" e o "espaço matemático", que correspondem aos conceitos apreensão" e "por postulação", respectivamente. Vejam-se, ainda, suas Proposições I e II. 
extensões dos resultados iniciais. $O$ insucesso em qualquer ponto exige que nôvo modêlo seja elaborado e submetido ao mesmo processo.

Conforme acima sugerimos, tanto o estágio de desenvolvimento de uma disciplina como a situação problemática exigem atenção, pois um ou mais dos métodos supra-referidos caracterizam cada estágio. Isto é, o método indutivo caracteriza o estágio da «análise do problema-área», e assim por diante.

O esmero implícito da interação de estágio e método, todavia,

não deve ser exagerado. Talvez essa simples ilustração ${ }^{1} \triangle^{3}$ con duza a uma representação mais perfeita da dinâmica da seqüência total do que a imagem $1 \rightarrow 2 \rightarrow 3$ sugerida pelos três estágios. Tentativas de incluir progressivamente áreas de problemas cada vez mais largas na teoria formulada dedutivamente, implica em complexidade ainda maior. Devido à sua extensão, a área de problema abrangida pela teoria formulada dedutivamente, pode (e parece que sempre) exigir mais do que simples acumulação de número cada vez maior de dados experimentais a respeito de velhos conceitos. O processo é aproximadamente êste: novos problemas devem ser analisados; novos dados talvez tenham que ser coligidos, sob novos conceitos do estágio de História Natural ("conceitos por apreensão"); e modificações na teoria existente e nos conceitos básicos do terceiro estágio do inquérito ("conceitos por postulação") podem ser necessários para expressar ambos, os velhos e os novos dados experimentais.

Muito da complexidade da análise científica gira em tôrno dos "conceitos por apreensão" e "conceitos por postulação". Considere se o problema entre Galileu e a Inquisição. A disputa não se relacionava com a ocorrência ou não de eclipses. Ao contrário, relacionava-se com as conseqüências de duas teorias formuladas dedutivamente, que implicavam na explicação do mesmo fenômeno. O sistema de Galileı admitia o movimento da terra em tôrno do sol; o sistema admitido pela Inquisição considerava a terra como o centro do universo. Do ponto-de-vista dos dados sensoriais, nada havia a escolher entre os dois sistemas: os postulados de nenhum dêles podiam ser diretamente percebidos. Havia, porém, certas proposições derivadas do sistema de Galileu que explicavam e prediziam um fenômeno - os eclipses - os quais, de acôrdo com o sistema da Inquisição, eram simplesmente atos da vontade de Deus. Para a predição dos eclipses, então, a teoria de Galileu teve utilidade e a da Inquisição, não.

Todavia, isso não resolveu a questão, pois os postulados de Galileu não podiam ser experimentados diretamente. Assim, não eram necessàriamente os únicos que podiam contar a favor dos 
eclipses. O problema então consistia em demonstrar que nenhuma outra teoria ou os postulados dela derivados eram passiveis de explicação satisfatória. Ou (mais acertadamente) tratava-se de verificar se a teoria e os postulados originais podiam estender-se a outros fenômenos. Resultados negativos poderiam forçar a modificação do original, ou o desenvolvimento de outra teoria-mater. Como expressou Einstein, é o processo assintático de aproximação da realidade. $\left({ }^{19}\right)$

"Ciência é a tentativa de fazer a diversidade caótica da nossa experiência sensorial corresponder a um sistema de raciocinio lógico. Nesse sistema cada experiência por si deve ser de tal forma correlacionada com a estrutura teórica, de modo que a coordenação resultante seja única e convincente".

O trabalho preliminar, todavia, exige bastante artificialismo. E' inexato, por exemplo, considerar o estágio da ciência-natural como mero estágio de acumulação de "fatos-puros" que simplesmente fornece a matéria-prima para os moinhos teóricos do estágio final. Em contraste, fatos cientificamente úteis não são achados "puros" ou "imediatamente apreendidos" mas sob a forma de dados simplificados, trazidos por conceitos que implicam em relações apresentadas em forma de proposição. $\left({ }^{20}\right)$ Conseqüentemente, mesmo nos estágios preliminares, já se está lidando com um baixo nive! de teoria mais do que com "fatos puros".

O produto dêsse estágio da História Natural é um sistema que poderia ser denominado de "teoria intermediária", em contraste com a teoria de alto nível do terceiro estágio. O sistema de Galileu, para ilustrar a importância dessa teoria de nivel médio, baseava-se em dados percebidos e apresentados em têrmos de conceitos por apreensão, tais como "escuridão", "claridade", "tempo", "posição" e "fases" e também a confirmação repetida de certas relaçốes teóricas de baixo nível, envolvendo êsses conceitos, bem como o sol e a lua. O desenvolvimento dessa teoria de nivel

(19) Albert Einstein, "Considerations Concerning the Fundaments of Theoretical Physics", in Science, vol. 91 (24 de maio de 1940), pág. 487 (grifo do autor).

(20) Richard C. Shrldon, "Some Observations on the Theory in Social Science", editado por Talcott Parsons e Ewdard A. Shils, Toward a General Theory of Action (Cambridge, Mass., Harvard University Press, 1951), páginas 36-37, observa o seguinte: "Enquanto fôr verdade que tôda observação é em têrmos de um esquema conceitual e que o fato é um dado sensorial em têrmos de esquema conceitual, isso não significa que se deva ter uma teoria completamente elaborada para fazer quaisquer observações". 
médio é, assim, da maior importância para a ciência, e a seção IV trata do assunto com algum detalhe.

Essas considerações delineiam o quadro metodológico necessário ao esfôrço cientifico. Em resumo, o vocábulo "ciência" deveria ser mais usado como verbo do que como substantivo, mais como "fazendo" do que "sendo": fazendo, no sentido de isolar e resolver problemas; como o desenvolvimento de conceitos apropriados e técnicas de estudo, abrangendo áreas de problemas dentro de uma rêde teórica de compreensividade crescente e de modo atitocorretivo. O papel desempenhado pela teoria é significativo nesse "fazendo". Resumidamente, alguns dos usos da teoria são:

1. agregativo, indicando o conjunto de relações que são encaradas como existentes em alguma universalidade de dados empíricos;

2. sugestivo, como a possibilidade de relações de ordem prática, além daquelas para as quais a teoria especificamente provê;

3. premonitótio, permitindo conhecer antecipadamente as relações em alguma universalidade de dados empiricos;

4. corretivo, que permite continuada reverificação interna, por meio da comparação das conclusões oriundas das propriedades da teoria com as observações empíricas.

Essa breve discussão, porém, não é o bastante para reconciliar a ciência com a Administração Pública. Mais estudo da questão "fato-valor" e exame mais detalhado dos lugares dos conceitos pela apreensão na ciência e teoria são indispensáveis para completar a tarefa.

\section{III - CIÊNCIA}

D. Os Problemas de Fato e Valor

O desenvolvimento das ciências naturais exigiu a separação de duas espécies de questões: Qual ê o caso?, e Qual Deveria ser o Caso? Essas indagações deveriam ser chamadas, respectivamente, questões de fato e valor. O desenvolvimento das ciências sociais e das naturais, também, depende muito da clara distinção dessas questões.

A observação não é nova para o cientista político, naturalmente. Aristóteles separou-as distintamente nas suas obras Politica e Ética; Bacon elogiou Maquiavel por sua façanha ao mantê-la em $O$ Principe; e foram bem freqüentes na literatura as tentativas de separar as duas questões, como uma condição prévia in- 
dispensável ao desenvolvimento do estudo cientifico da política ou da Administração Pública. ( $\left.{ }^{21}\right)$

O pêso dessa precaução, todavia, não foi suficiente para deixar a marca de sua distinção no trabalho de numerosos estudiosos de Administração Pública. Muitos estudiosos continuam a trabalhar de ambos os lados da rua, muitas' vêzes implícita e simultâneamente. Dentre as diversas tentativas infrutiferas para estabelecer uma distinção "fato-valor" em Administração Pública, avulta o trabalho de Simon. Foi enorme seu impacto. ${ }^{(22}$ ) Parcialmente, devido ao reconhecimento da estatura de Simon e, parcialmente, por causa de sua defesa impessoal da distinção do fato-valor na disciplina, a distinção e o lugar desta distinção na ciência da Administração Pública tem sido geralmente confundidos na literatura com sua distinção e o lugar em sua ciência da Administração Pública. Dessa forma, a distinção fato-valor na disciplina foi o alvo das críticas dirigidas contra Simon pela escolha de um veículo metafísico e seu argumento em geral. Tal como no caso com a questão mais ampla "ciência-arte", contudo, partidários e oponentes têm pôsto de lado a questão fato-valor. Aparentemente, a batalha acadêmica foi considerada não compensadora.

O armistício foi interrompido aqui. A tarefa foi iniciada. Pois, do lado do "fato", parte das dificuldades dos estudiosos com relação às posições assumidas por Simon, origina-se de sua preocupação com as tomadas de decisão em nivel abaixo e os fatos aparentemente "firmes" associados a êles. Todavia, os "fatos" são "fracos". $\mathrm{Na}$ verdade, êles são considerados existindo sòmente enquanto os conceitos se desenvolvem e, muito mais ainda, inclusive enquanto os enunciados teóricos das relações empíricas de tais conceitos são verificados. O processo é semelhante para os "fatos físicos" e os "fatos sociais".

A tarefa de separar o bebê analítico da água do banho, continua, porém, inacabada. Dessa forma, dá-se mais ênfase aqui ao lado do "valor" na questão fato-valor e seu lugar numa ciência da Administração Pública. Para começar, é preciso isolar duas classes gerais e subprocessos dentro do "processo" cientifico mais amplo: (1) o processo para chegar às conclusões e as próprias

(21) A distinção foi feita de modo pitoresco no documento que é considerado como a certidão de nascimento da Administração Pública, o "The Study of Administration" de Woodrow Wilson, in Political Science Quarterly, vol. 2, (Julho de 1887), págs. 197-222. O exemplo que escolheu foi de tomar por empréstimo a avançada técnica de afiar facas dos bandidos indianos, sem fazer o mesmo com a respectiva motivação.

(22) WALDO reflete êsse impacto ao dedicar mais de nove páginas das 70 da sua monografia The Study of Public Administration, à análise da posição esboçada por SImon no seu Aciministrative Behavior. 
conclusões; e (2) aquêles processos que não afetam diretamente o desenvolvimento das conclusões. Estão incluídos nessa última classe; a seleção do problema a ser investigado, a limitação de usos do homem e outros materiais envolvidos, e a determinação do que deve ser feito com os resultados. Na classe 1, um conjunto particular de valores — os "valores da ciência" - deve ser observado. $\left({ }^{23}\right)$ Valores em qualquer sentido - o têrmo tem sido aplicado promiscuamente a referentes provocados por motivos de ordem de custo econômico - podem ser pertinentes à classe 2 do "processo cientifico".

Em contraste, o pêso esmagador da primitiva opinião em Administração Pública, tomou a posição indefensável de que a definição técnica do campo como "administração" mais do que "politica" - impedem a consideração de valores. Da mesma forma que Simon, seu método através do "positivismo lógico" tornou impossivel a necessária conexão de valores nas classes 1 e 2. De fato, alegourse que o sistema lógico de Simon, lògicamente impediu de estudar alguma coisa de qualquer modo, pois há elementos de valor envolvidos em tôda pesquisa, desde a decisão até o estudo avançado.

Os valores, porém, desempenham um papel mais importante do que o acima descrito. Considera-se sua parte nas distinções fundamentais entre os tipos de pesquisas. Assim, as investigações empíricas devem distinguir-se em têrmos de incidência ou não-incidência de certos valores-objetivos na classe 2 do processo cientifico:

1. Uma categoria "empirica", que tem como objetivo a descrição e explanação de aspectos selecionados do mundo real; e

2. Uma categoria "bem fundamentada, empirica" que pressupõe uma determinada meta, e tenta indicar as condições necessárias à conquista da mesma, ou dela resultantes, através de uma descrição e interpretação do mundo objetivo.

Há um terceiro tipo de pesquisa também importante, embora seus modelos não tenham necessàriamente contrapartida empíricas. Essa categoria "racional" ou "utópica" inclui argumentos por análise lógica ou desenvolvimento de proposições sôbre juizos de valor, definições e axiomas que podem ser completa ou parcial-

(23) Robert Merton Social Theory and Social Structure (Glencoe, Illinois, Free Press, 1949), págs. 309 e seguintes, apresenta 4 importantes características do "conjunto de valores culturais e mores governando as atividades ditas cientificas": universalismo; distribuição de resultados; desinterêsse e ceticismo o:ganizado. 
mente independentes do mundo empirico. No nível do interêsse sistemático, é por meio da geometria que melhor se ilustra êsse trabalho. Na área social, a obra de Max Weber sôbre a burocracia, de modo semelhante, partindo de um conjunto de valores, também discute a respeito de uma burocracia "ideal" (no sentido da realização ótima dos seus fins). Não estava êle, fundamentalmente, interessado na possibilidade ou não do sistema poder corresponder a um sistema prático.

Os trabalhos utópicos têm que ser manejados com muita cautela, com valores desempenhando importante papel no processo. As propriedades do sistema, dessa forma, devem ser julgadas contra nossos valores, para a determinação de sua desejabilidade. Além do mais, as proposições do sistema devem ser verificadas por meio de dados empíricos, a fim de determinar o grau de realidade que espelham. Não há nisso excesso de minúcias. A aplicação dêsses dois testes à teoria tradicional de organização, por exemplo, demonstra que o caso tem relevância vital no tocante ao problema das áreas de interêsse para o estudioso da administração pública. $\left({ }^{24}\right)$ Em têrmos de sistema racional per se, todavia, tais considerações não são relevantes. O sistema é apenas julgado como um sistema na medida da compreensão e do rigor do seu desenvolvimento, a partir de suas bases, dos objetivos, definições e axiomas. A natureza dos valores, definições e axiomas é irrelevante. $O$ insucesso em distinguir entre êsse trabalho quando "usado" (isto é, como modêlo, a partir do qual certas relações são padronizadas) e como "sistema", tem sido fonte de considerável confusão.

A literatura está pontilhada com as provas do descaso dêsses tipos de teorias e, conseqüentemente, de valores. E' ilustrativo que um dado empírico de significação (que pode ser parte de uma teoria empírica) possa ser interpretado como necessário e desejável guia de comportamento (guia êsse que deve expressar-se como uma teoria empírica baseada em objetivos). Mais comumente, um método utópico é considerado empírico. A teoria tradicional de organização, por exemplo, reflete ambos os equivocos. De forma análoga, as laboriosas explicações a respeito da enorme diferença entre a República e as Leis de Platão, refletem tal imprecisão. Os estudiosos geralmente dizem que Platão escreveu as Leis quando tinha ido semear, mas o que êle realmente quis dizer está na República. Os trabalhos realmente diferem, não porém pelas razões inventadas acima. Platão distinguiu um mo-

(24) Robert T. Golembiewski, "Toward the New Organization Theories: Some Niotes on "Staff"," in Midwest Journal of Political Science, vol. 5 (Agôsto de 1961), págs. 237-259. 
dêlo utópico (a República) do modêlo prático, de fins utilitários (as Leis). Muitos de seus críticos têm feito menos. A obra de POPPER, por exemplo, The Open Society and Its Enemies, apoia-se firmemente numa confusão de tipos de teorias.

Essas considerações implicam num ponto claro, para os fins atuais. A Administração Pública como ciência, então, deve ter três fundamentos teóricos. O primeiro seria a teoria empirica, ou "pesquisa básica", que é a procura das inter-relações e suas circunstâncias. O segundo seria uma teoria empírica baseada em fins preestabelecidos, ou uma "orientação politica". Tais teorias focalizam como se consegue aquilo que se procura, dadas as relações existentes no mundo ou que possam ser utilizadas. Os sistemas utópicos de teorias constituem o terceiro grupo. Devem ajudar o trabalho em outras áreas, se houver cuidado. Êsse papel restrito contrasta profundamente com a preocupação histórica, e até inconsciente, muitas vêzes, da teorização utópica nas ciências sociais em geral, e particularmente na Administração Pública.

Conseqüentemente, os valores devem ter um lugar muito importante na Administração Pública como disciplina completamente desenvolvida. E' verdade que, na teoria empirica, limitam-se os lugares dos valores. Mas sua importância na teoria empirica fina lista - que na orientação politica da disciplina sempre deve ser central - dificilmente pode ser superestimada. Os estudiosos da disciplina certamente devem dar considerável atenção à "boa vida", à ordem preferencial de valores, como aparecem nas políticas. A teoria empírica pode ajudar a aguçar o contraste entre conjuntos de valores, mas não pode fazer a escolha. Uma vez feita a escôlha do desejado estado dos negócios, naturalmente, uma teoria empirica mostrará a direção das ações necessárias ao implemento da decisão .

Não é preciso dizer, então, que o método aqui não implica na trivialidade das questões de valores na Administração Pública. Contrapartidas modernas da Ética de Aristóteles deverão sempre ocupar inúmeros estudiosos. A posição aqui é simplesmente esta, em abstrato: que o estudo científico das relações empíricas é uma importante área de interêssse - e na Administração Pública fica descuidada; que, além do mais, trabalho muito mais importante pode ser feito nessa área, antes de conseguir-se qualquer acôrdo significativo no tocante aos valores; e, finalmente, que não há desculpas para confundir os problemas de valor e os de ordem prática.

Apoio adicional ao lugar dos valores na disciplina permitirá apenas a limitadas áreas da Administração Pública suportar a ênfase proposta no presente método empírico. Essa condição limi- 
trofe foi negligenciada pelos primitivos postulantes de uma ciência da Administração Pública. Os que propugnam no presente pela necessidade de uma metodologia científica não devem correr o mesmo risco. Esse é o sentido, por exemplo, da luminosa análise de pequenos grupos, geralmente pelos estudiosos de Administração Pública e de Ciência Política. $\left({ }^{25}\right)$ A literatura de pequenogrupo mostra sobejamente o que se pode fazer com o método empírico. Além disso, o pequeno-grupo é significativo em muitas áreas de interêsse para os cientistas políticos: no estudo da organização, da votação e da opinião, de jurados e juizes, e outros semelhantes. Ao mesmo tempo, o uso de resultados e técnicas de pequenos grupos obrigou aos estudiosos a aprender e praticar os métodos de pesquisas empíricas. Tal combinação de necessidade e treinamento, em suma, dá impeto substancial à marcha em busca de uma ciência empírica.

Não é preciso, afinal de contas, haver inimizade entre valor e ênfase empirica. De fato, ambos podem ajudar-se mùtuamente. Assim, os valores podem constituir importantes dados empíricos. $\left({ }^{26}\right)$ Isso não quer dizer que os valores possam ser "provados" ou "refutados". Mas podem ser determinados (o que é uma tarefa empírica); podem ser analisados por suas implicações, inconsistências, ou conseqüências (tarefa racional); ou podem ser comparados ao comportamento real (combinação dessas tarefas). A lado disso, os valores podem servir como "tendências" ou dados para julgamentos empiricos. Isto é, a incidência de crenças de que a segregação é um mandamento divino constitui dado importante para o julgamento de uma política realista de cumprimento das decisões da Suprema Côrte em determinada cidade.

\section{IV - CIÊNCIA: CONCEITO POR COMPREENSÃO E OPERAÇÕES}

Como disciplina, a Administração Pública já realizou grande parte do seu trabalho no estágio de análise dos problemas. Conseqüentemente, quaisquer desenvolvimentos metodológicos significativos dessa disciplina deverão conduzi-la ao estágio da História Natural. A compreensão do estágio é, então, da maior importância para os estudiosos da disciplina, especialmente tendo em vista que a literatura raramente tem ido além da preliminar ciên-

(25) Uma aplicação da literatura da teoria de organização pode ser encontrada em Golembiewski, Behavior and Organization (Chicago, Rand Mc Nally, 1962).

(26) Para ilustrar a importância dos valores na administração e do seu tratamento empirico, veja-se PETER M. BL.Au, The Dynamics of Bureaucracy' (Chicago University of Chicago Press, 1955). 
cia-arte e do problema fato-valor, levantados pelas tentativas infrutiferas de estabelecer a disciplina como ciência.

Focalizaremos a seguir dois elementos cruciais do estágio da História Natural, isto é, os "conceitos por apreensão" e as "operações". O desenvolvimento dêles torna-se necessário quando o uso da "linguagem diária" - com sua falta de precisão e de objetivo - começa a pagar dividendos decrescentes. O problema é o mesmo para as ciências físicas e sociais.

O desenvolvimento de conceitos por apreensão pode parecer ilusòriamente simples. Os conceitos dêsse tipo e as operações correspondentes com as quais estamos mais familiarizados (por exemplo, pêso, gramas; altura, metros; etc.) parecem naturais. Seu uso habitual, embora històricamente breve, também cria uma forte impressão em sua existência permanente. Tais conceitos, todavia, são apenas construções convenientes que se desenvolveram sòmente através de enorme esforç̧o. Demais, devem ser as proverbiais moscas de um verão cujo outono será um fracasso.

A grandeza da dificuldade do desenvolvimento de conceitos por apreensão deve ser oriunda da própria natureza da tarefa: (1) a determinação de quais dos aspectos de determinada seção da experiência prática são de fato significativos; e (2) o desenvolvimento de conceitos claramente definidos, não superpostos e unidimensionais - ou definições nominais - dêsses aspectos. $\left({ }^{27}\right)$ O processo de desenvolvimento, então, deve ser descrito como solução superlativa dessas duas tarefas. Uma "solução" custa caro e é apenas uma solução provisória. Em outras palavras, é preciso dedicar muito trabalho na verificação dos conceitos propostos, para determinar se êles ajudam a fazer a ordem de experiências. Além disso, qualquer conceito deve ser continuamente avaliados em têrmos de sua aplicabilidade a maiores conjuntos de relações. Parece não haver um limite finito para o processo, embora alguns conceitos permitam predizer de modo bem satisfatório e explicar muitos propósitos.

No estágio da História Natural é grande a importância dos conceitos por apreensão, embora seja penoso seu desenvolvimento. $\mathrm{Na}$ realidade, constituem êles a medula dêsse trabalho. Como notou Merton: "os conceitos, então, constituem as definições (ou prescrições) do que deve ser observado; são as variáveis dentro das quais as relações empíricas devem ser procuradas".

(27) Para discussão completa das áreas dêsses problemas, veja-se WIL. liam J. Goode e Paul K. Hatt, in Methods in Social Research (Nova Iorque, McGraw Hill, 1952), págs. 41-53; e Merton, op. cit., págs. 87-90.

(28) Mfrton, op. cit., págs. 41-44. 
As importâncias e os problemas do desenvolvimento de conceitos por apreensão podem ser simultâneamente demonstrados. Assim, o grau de solução dos problemas de conceituação produz uma complexa rêde de efeitos. O grau de solução, por exemplo, determina muito significativamente a natureza dos resultados obtidos, quando os conceitos são incorporados em hipóteses e empìricamente testados. Consideremos, para ilustrar, a conceituação nominal que se aplica a duas ou mais classes octogonais de fenômenos. Para simplificar consideràvelmente, grande número de testes em duplicata pode produzir resultados contraditórios. Como os "pesos" de várias classes de fenômenos incluidos podem variar de teste para teste - dependendo da distribuição por "pesos" as relações observadas podem variar ou ser contraditórias de um estudo para outro. Além disso, a solução de dois problemas de conceituação também determina a que distância e com que velocidade o desenvolvimento da teoria do nivel-médio pode prosseguir e quando poderá começar a teoria do desenvolvimento dedutivo. Deve-se entender por teoria de nível-médio o sistema expressando as relações existentes entre os conceitos por apreensão.

Êsses comentários, por sua vez, sugerem a importância da definição operacional de conceitos por apreensão. Para indicar sucintamente a função da definição operacional, os conceitos em si próprios não são fenômenos. Êles se referem aos fenômenos via construção de sensações de variados sentidos. Elemento importante para a utilidade de qualquer conceito é, então, o conjunto de operações por meio dos quais aquêle conceito pode ser medido. Dois elementos distintos podem ser abrangidos: a validade da operação (refere-se a operação ao mesmo aspecto dã realidade apresentado pelo conceito?); e a segurança da operação (qual o grau de coerência entre diversas observações do mesmo material?)

Isso abafa um problema diabólico. A segurança da administração oferece menos desafio, e o grau necessário de ocerência das interobservações pode ser arbitràriamente exigido. (29) Mas a segurança operacional não é suficiente. A validade operacional é mais complexa e igualmente importante. A validade nominal cla operação é um fator. Finalmente, porém, o teste é a dupla utilidade da operação: na predição segura de relações empíricas; e na explicação cada vez mais completa do mundo objetivo.

(29) O método de determinar a segurança pode ser um problema significativo, porém especialmente no primitivo desenvolvimento de uma operação especifica. Veja-se Launor F. Carter, William Haythorn, Beatrice Meirowitz e John Lanzetta, "The Relation of Categorizations and Ratings in the Observation of Group Behavior", in Human Relations, vol. 3 (Julho de 1951), páginas $239-254$. 
Dessa forma, o problema da validade da operação está ligarlo à segurança, à coerência, clareza e significação da definição nominal de que a operação procura cuidar.

O desenvolvimento, dos pares de conceito-operação é, pois, um assunto complexo. Poder -se-ia armar uma equação de quatro variáveis. Essas quatro variáveis são: a definição conceitual ou nominal; a segurança das operações que a definem; a validade dessas operações e o nivel de teoria em que o conceito pode ser assentado. Tudo isso simplifica demasiado o problema, pois só há "soluções" temporárias.

Essa complexidade pode ser ilustrada, considerando-se o de, senvolvimento do conceito de "coesibilidade", $\left({ }^{30}\right)$ uma dimensão que se mostrará cada vez mais útil para compreensão do com. portamento nas organizações. Antigas conceituações acentuaram que a "coesibilidade" referia-se às atrações positivas de um grupc por seus membros e, conseqüentemente, as operações iniciais baseavam-se em dados indicando amizades ou ligações de membros de grupos assemelhados. Alguns resultados que sustentavam êsse método antigo foram obtidos, mas os resultados em conflito logo forçaram as modificações, tanto conceituais como operacionais. Por exemplo, conceitualmente, a coesibilidade foi apurada para referir-se à atração resultiante do grupo. Sem qualquer dívida, alguns dos dados primitivos estavam em conflito pelo fato de que as atrações positivas deviam ser contrabalançadas ou superadas pelas características que tornavam o grupo pouco atraente. Medidas "parciais", operacionalmente relacionadas, tais como aquelas basea:ias em preferências pessoais, foram deslocadas por medidas "resultantes", derivadas das respostas a perguntas como: a que ponto deseja você permanecer como membro dêste grupo? Essas modificações refletiram-se em resultados mais sólidos.

Tudo isso parece bastante razoável, embora se possa indagar porque os pesquisadores não viram o óbvio desde $\mathrm{o}$ início. Um olhar retrospectivo torna as coisas mais claras, mas ainda permanecem abertas importantes questões relativas à coesibilidade. Dessa forma, associa-se a alta coesibilidade com a alta ou a baixa produtividade. Isso é razoável, desde que a alta coesibilidade implica em significativo contrôle sôbre o comportamento dos membros do grupo, e uma vez que a alta ou baixa produtividade implica em alto grau de contrôle do seu comportamento. Em certọ sentido, porém, seria bastante desejável maior especificação das condições - estilo de liderança, características de personalidade, estrutura

(30) Veja-se Robert T. Golembiewski, "Management Science and Group Behavior; Work-Unit Cohesivenese". in Journal of the Academy of Management, vol. 4 (Agôsto de 1961), págs. 87-99. 
da organização, e outros - sob as quais a coesibilidade estará associada com um ou outro dêsses níveis de produtividade. Isso dá uma idéia do vulto do trabalho ainda por fazer, e ninguém deveria extranhar se as mudanças na coesibilidade, tanto conceituiis como operacionais, fôssem chamadas a realizar o trabalho, nem que essas transformações pudessem depois parecer óbvias.

O problema do tratamento científico de dados experimentais não promete solução imediata ou sem grandes esforços. Todavia, a colocação do problema sob essa forma, é em si própria enorme passo à frente no sentido de uma metodologia mais rigorosa da pesquisa cumulativa. Pelo menos, a metafórica medida elástica será um instrumento inadequado pois, embora os conceitos possam ser tachados de "subjetivos", sê-lo-ão apenas em sentido muito particular. Relações hipotéticas entre os conceitos podem ser verificadas em estudos que os reproduzam, desde que suas operações sejam especificadas. Consequiências lógicas de certos achados científicos podem ser confirmadas ou refutadas. São as bases para firmes e disciplinados esforços cumulativos. Isto é, essa séria questão de tentar saltar por cima dos conceitos e suas operações, de menor para maior amplitude, de descobrir e adicionar mais e mais relações empíricas, tem uma dúplice função. Demonstra-se a utilidade (ou realidade) dos conceitos e suas funções. Além do mais, tece as malhas de uma teoria demasiado ampla, ou uma única e convincente explanação das relações empiricas.

As definições nominais e operacionais constituem, pois, uma alternativa para tradição acadêmica pessimista que defende a adoção de uma Weltanschaung $\left(^{*}\right)$ - um demônio ou um deus, como expressou Weber - e interpretar a realidade de conformidade com êsses têrmos. E' uma tradição, afinal, que deve ser ultrapassada pelo trabalho em busca de uma área cientifica na Administração Pública e de uma Ciência Politica.

Não visam esas considerações a menosprezar os estudos descritivos da vida nas organizações administrativas, que tanto têm enriquecido nossos conhecimentos, nem implicam em considerá-los superados. A obra dos Macmahons, Milletts, Druckers, Dimocks e outros, teve e continuará a ter uma significação insofismável. Tais trabalhos, porém, também têm seus limites. Assim, para que a Administração Pública possa manter sua contribuição ao desenvolvimento das Ciências Administrativas, é evidente que maior atenção deverá merecer sua passagem do estágio de Ciência $\mathrm{Na}$ tural para outro mais avançado.

N.T. - Cosmovisão ou mundividência, de inspiração divina ou demonológica. (Extraido da "Revue Internationale des Sciences Administratives" - Vol. XXX n' 2). 